\title{
ВЛИЯНИЕ ПРЕПАРАТА МЕЛЬДОНИЙ НА КЛИНИЧЕСКОЕ ТЕЧЕНИЕ ВОСПАЛИТЕЛЬНЫХ ЗАБОЛЕВАНИЙ ПАРОДОНТА У БОЛЬНЫХ ИБС, ПЕРЕНЕСШИХ ИНФАРКТ МИОКАРДА
}

\section{THE EFFECT OF MELDONIUM ON THE CLINICAL COURSE OF INFLAMMATORY PERIODONTAL DISEASES IN PATIENTS WITH CORONARY ARTERY DISEASE WHO HAVE HAD MYOCARDIAL INFARCTION}

\section{Inalov \\ S. Minkailova}

Summary. The study evaluated the effect of Meldonium on the periodontal condition in patients with CGP and after MI. Patients were treated with Meldonium at a dose of $250 \mathrm{mg} \times 2$ times a day for 3 months.

Keywords: myocardial infarction, cardiovascular diseases, Meldonium preparation, chronic periodontal diseases, clinical and instrumental examination.
Иналов Даниял Мухтарахмедович

ФГБОУ ВО «Дагестанский государственный медицинский университет» МЗ РФ

Dgma_mo@mail.ru

Минкаилова Санера Расуловна

Доцент, ФГБОУ ВО «Дагестанский государственный Медицинский университет» МЗ РФ minkailova76@mail.ru

Аннотация. В исследовании была проведена оценка влияния препарата Мельдоний на состояние пародонта у пациентов, страдающих ХГП и перенесших ИМ. Больным было проведено лечение препаратом Мельдоний в дозе 250 мг х 2 раза в день в течение 3-х месяцев.

Ключевые слова: инфаркт миокарда, сердечно-сосудистые заболевания, Препарат Мельдоний, хронические заболевания пародонта, клинико-инструментальное обследование.
B работах исследователей показано, что Мельдоний способен обеспечить замедление скорости ß-окисления ЖК в митохондриях и ограничение транспорта ЖК через клеточные мембраны, что актуально в условиях избыточного накопления ЖК; снижает расход кислорода в организме в целом, обеспечивает процессы ишемического прекондиционирования за счет снижения скорости трансмембранного транспорта ЖК, ацил-СоА и ацилкарнитина в клетки, уменьшения потребления кислорода, замедления $\beta$-окисления ЖК и повышения скорости биосинтеза $\gamma$-бутиробетаина; индуцирует биосинтез NO в эндотелии кровеносных сосудов, уменьшая сопротивление периферических кровеносных сосудов и агрегацию тромбоцитов, увеличивая эластичность мембран эритроцитов; позволяет минимизировать метаболический ацидоз, развивающийся в результате активации анаэробного гликолиза и накопления молочной кислоты. $[1,2,3]$. При ХГП, как и при любом хроническом воспалительном процессе имеет место нарушение микроциркуляции и окислительно-восстановительных процессов. Препарат Мельдоний, показавший многоплановый защитный для тканей эффект в качестве лечебного средства в стоматологии не применялся.
В исследовании была проведена оценка влияния препарата Мельдоний на состояние пародонта у пациентов, страдающих ХГП и перенесших ИМ.

В настоящей работе представлены результаты клинико-инструментального исследования пациентов стоматологической поликлиники ФГБОУ «Дагмедуниверситет» МЗ РФ, и в ГБУ «РКД» МЗ РД, перенесших инфаркт миокарда и состоящих на диспансерном учете.

Было обследовано 498 пациентов, которым была проведена коронарография по поводу ИБС. Больные были консультированы стоматологом на наличие патологии полости рта и им был выставлен диагноз ХГП той или иной степени тяжести. Все пациенты были разделены на группы:

1. 213 мужчин, перенесших ИМ, средний возраст $58,9 \pm 0,5$ лет.

2. 134 мужчины, без перенесенного ИМ - средний

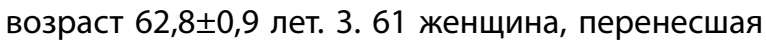

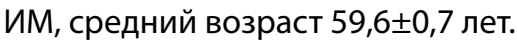

3. 90 женщин без перенесенного ИМ, средний возраст которых составил $61,1 \pm 1,0$ лет. 
Таблица 1. Динамика степени тяжести поражения пародонта у больных ХГП, перенесших ИМ при лечении Мельдонием

\begin{tabular}{|l|l|l|l|l|}
\hline Степень тяжести ХГП & $\begin{array}{l}\text { Основная гр. } \\
\text { до лечения }(\mathbf{n = 1 4 0 )}\end{array}$ & $\begin{array}{l}\text { После лечения } \\
(\mathbf{n = 1 4 0 )}\end{array}$ & $\begin{array}{l}\text { Контрольная гр. } \\
\text { до лечения (n=90) }\end{array}$ & После лечения (n=90) \\
\hline ХГП легкой ст. & $12(8,6 \%)$ & $28(20 \%)$ & $9(10,1 \%)$ & $11(12,2 \%)$ \\
\hline ХГП средней ст. & $76(54,3 \%)$ & $64(45,7 \%)$ & $52(57,7 \%)$ & $48(53,3 \%)$ \\
\hline ХГП тяжелой ст. & $52(37,1 \%)$ & $48(34,3 \%)$ & $29(32,2 \%)$ & $31(34,4 \%)$ \\
\hline
\end{tabular}

Таблица 2. Динамика симптома кровоточивости десен CPITN1 у больных ХГП, перенесших ИМ при лечении Мельдонием в зависимости от тяжести заболевания

\begin{tabular}{|l|l|l|l|l|}
\hline Степень тяжести ХГП & $\begin{array}{l}\text { Основная гр. } \\
\text { до лечения }(\mathbf{n = 1 4 0 )}\end{array}$ & После лечения (n=140) & $\begin{array}{l}\text { Контрольная гр.до } \\
\text { лечения (n=90) }\end{array}$ & После лечения(n=90) \\
\hline ХГП средней ст. & $14(10 \%)$ & $6(4,4 \%)$ & $6(7 \%)$ & $3(3,9 \%)$ \\
\hline ХГП тяжелой ст. & $18(13 \%)$ & $11(7,6 \%)$ & $9(10 \%)$ & $6(6,8 \%)$ \\
\hline
\end{tabular}

Таблица 3. Динамика цифровых значений наличия зубного камня CPITN2 у больных ХГП, перенесших ИМ при лечении Мельдонием в зависимости от тяжести заболевания

\begin{tabular}{|l|l|l|l|l|} 
Степень тяжести ХГП & $\begin{array}{l}\text { Основная гр. } \\
\text { до лечения }(\mathbf{n = 1 4 0 )}\end{array}$ & $\begin{array}{l}\text { После лечения } \\
(\mathbf{n = 1 4 0 )}\end{array}$ & $\begin{array}{l}\text { Контрольная гр.до } \\
\text { лечения (n=90) }\end{array}$ & После лечения(n=90) \\
\hline ХГП легкой ст. & $41(29,2 \%)$ & $19(13,6 \%)$ & $33(36,6 \%)$ & $24(26,6 \%)$ \\
\hline ХГП средней ст. & $31(22,1 \%)$ & $14(10,0 \%)$ & $39(43,3 \%)$ & $32(35,5 \%)$ \\
\hline ХГП тяжелой ст. & $28(20,0 \%)$ & $18(13 \%)$ & $18(20,0 \%)$ & $12(13,3 \%)$ \\
\hline
\end{tabular}

Все больные имели стабильную стенокардию напряжения I-II функционального классов, часть пациентов страдала АГ III стадии, 1-2 степени, риск сердечно-сосудистых осложнений 4 степени [5]. Среди них, мужчины составили 44\%, женщины - 61\%. Сахарный диабет имел место у $16 \%$ мужчин и $38 \%$ женщин. Хронический гастрит вне обострения имел место у $81 \%$ мужчин и $34 \%$ женщин. Медикаментозную терапию клинических проявлений ХГП и ИБС проводили согласно стандартам лечения ХГП [6] и ИБС [7]. Для оценки эффективности влияния препарата Мельдоний на клинико-инструментальные проявления ХГП, путем простой рандомизации были отобраны 140 пациентов: 89 мужчин и 51 женщина, больных ХГП легкой, средней и тяжелой степени, принимавших помимо стандартного лечения ХГП и ИБС, препарат Мельдоний в дозе 250 мг х 2 раза в день в течение 3-х месяцев (основная группа). Средний возраст мужчин составил

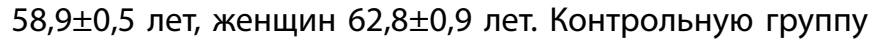
составили 90 пациентов - 55 мужчин, средний возраст

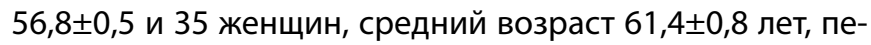
ренесших ИМ и имеющих ХГП легкой, средней и тяжелой степени и получавших традиционную терапию ХГП и ИБС. Рандомизация пациентов проходила путем простого подбрасывания игрального кубика. Клинико-инструментальное обследование проводилось до начала приема препарата Мельдоний и через 3 месяца.
Результаты влияния Мельдония на степень тяжести поражения пародонта представлены в Таблице 1.

Как видно из представленной Таблицы 1, в основной группе на 11,4\% увеличилось число лиц с легкой степенью ХГП, в то время как в контрольной группе число этих больных увеличилось лишь на 2,1\%. В группе пациентов со средней степенью тяжести ХГП, принимавших Мельдоний, число пациентов уменьшилось на 8,6\%, в контрольной группе -на 4,4\%. Среди пациентов с тяжелой степенью ХГП принимавших Мельдоний, после курса лечения число больных уменьшилось на 2,8\%, в контрольной группе - на 2,2\%.

В ходе исследования был проведен анализ влияния препарата Мельдоний на показатель нуждаемости в лечении CPITN. Полученные данные представлены в Таблицах $2,3,4,5$.

Как видно из представленной Таблицы 2, прием Мельдония уменьшил симптомы кровоточивости в группе со средней степенью заболевания улучшение этого показателя наблюдалось у 5,6\%, в контрольной - у 3,1\%. При тяжелой степени ХГП показатель кровоточивости десен в основной группе снизился на 5,4\%, в контрольной на $3,2 \%$. 
Таблица 4. Динамика пародонтальных карманов глубиной 4-5 мм СРITN3 у больных ХГП, перенесших ИМ при лечении Мельдонием в зависимости от тяжести заболевания

\begin{tabular}{|l|l|l|l|l|}
\hline Степень тяжести ХГП & $\begin{array}{l}\text { Основная гр. } \\
\text { до лечения (n=140) }\end{array}$ & $\begin{array}{l}\text { После лечения } \\
(\mathbf{n = 1 4 0 )}\end{array}$ & $\begin{array}{l}\text { Контрольная гр.до } \\
\text { лечения (n=90) }\end{array}$ & После лечения(n=90) \\
\hline ХГП легкой ст. & $27,9 \%$ & $17,4 \%$ & $26,5 \%$ & $20,4 \%$ \\
\hline ХГП средней ст. & $31,1 \%$ & $21,2 \%$ & $28,1 \%$ & $22,2 \%$ \\
\hline ХГП тяжелой ст. & $34,1 \%$ & $25,7 \%$ & $31,8 \%$ & $27,4 \%$ \\
\hline
\end{tabular}

Таблица 5. Динамика пародонтальных карманов глубиной 6 мм и более CPITN4 у больных XГП, перенесших ИМ при лечении Мельдонием в зависимости от тяжести заболевания

\begin{tabular}{|l|l|l|l|l|}
\hline Степень тяжести ХГП & $\begin{array}{l}\text { Основная гр. } \\
\text { до лечения }(\mathbf{n = 1 4 0 )}\end{array}$ & $\begin{array}{l}\text { После лечения } \\
(\mathbf{n = 1 4 0 )}\end{array}$ & $\begin{array}{l}\text { Контрольная гр.до } \\
\text { лечения (n=90) }\end{array}$ & После лечения(n=90) \\
\hline ХГП легкой ст. & $27,1 \%$ & $16,2 \%$ & $26,2 \%$ & $22,5 \%$ \\
\hline ХГП средней ст. & $25,9 \%$ & $19,3 \%$ & $25,6 \%$ & $20,2 \%$ \\
\hline ХГП тяжелой ст. & $30,3 \%$ & $26,7 \%$ & $25,9 \%$ & $21,4 \%$ \\
\hline
\end{tabular}

Таблица 6. Динамика ИПС(\%)у больных ХГП, перенесших ИМ при лечении Мельдонием в зависимости от тяжести заболевания

\begin{tabular}{|l|l|l|l|l|} 
Степень тяжести ХГП & $\begin{array}{l}\text { Основная гр. } \\
\text { до лечения }(\mathbf{n = 1 4 0 )}\end{array}$ & $\begin{array}{l}\text { После лечения } \\
(\mathbf{n = 1 4 0 )}\end{array}$ & $\begin{array}{l}\text { Контрольная гр.до } \\
\text { лечения (n=90) }\end{array}$ & После лечения(n=90) \\
\hline ХГП легкой ст. & $95,7 \pm 5,2$ & $82,4 \pm 3,8^{*}$ & $95,8 \pm 4,9$ & $87,6 \pm 4,2$ \\
\hline ХП средней ст. & $105,3 \pm 5,1$ & $93,6 \pm 4,1^{*}$ & $106,1 \pm 5,3$ & $98,4 \pm 4,7$ \\
\hline ХГП тяжелой ст. & $113,2 \pm 8,7$ & $101,5 \pm 6,2^{*}$ & $112,6 \pm 8,2$ & $107,2 \pm 7,1$ \\
\hline
\end{tabular}

$\mathrm{P}<0,05^{*}$

Как видно из представленной Таблицы 3, в процессе лечения Мельдонием число пациентов с зубным камнем в основной группе уменьшилось у пациентов с легкой степенью ХГП на 15,6\%, при средней степени заболевания - на 12,1, при тяжелой - на 7,0\%. В контрольной группе динамика была менее выраженной и при ХГП легкой степени составила 10\%, средней степени - 7,8, тяжелой $-6,7 \%$.

Как видно из представленной Таблицы 4, прием препарата Мельдоний положительно влиял на процентное содержание пародонтальных карманов глубиной 4-5 мм. При ХГП легкой степени показатель уменьшился на 10,5\%, при средней степени - на 9,9, при тяжелой на 8,4\%. В контрольной группе при ХГП легкой степени уменьшение произошло на 6,1\%, средней степени тяжести - на 5,9, тяжелой степени - на 4,4\%.

Как видно из представленной Таблицы 5, при ХГП легкой степени значения наличия пародонтальных карманов глубиной 6 мм и более в основной группе уменьшились на 10,9\%, средней степени тяжести - на 6,6, тяжелой степени - на 3,6\%. В контрольной группе эти показатели были соответственно равны 3,7\%, 5,4 и 4,5\%.
При изучении динамики показателей реопародонтографии на фоне лечения ХГП было показано снижение ИПС (Таблица 6).

Как видно из представленной Таблицы 6, под влиянием препарата Мельдоний у больных ХГП легкой степени ИПС достоверно снижался в группе с легкой степенью заболевания на 13,3\%, средней степени - на 11,7, тяжелой степени - на 117\%. В контрольной группе также имело место улучшение показателя периферического сопротивления при легкой степени ХГП - на 8,2\%, средней степени - на 7,7, тяжелой - на 5,4\%.

Динамика показателей РИ под влиянием курсового лечения препаратом Мельдоний представлена в Таблице 6.

Как видно из представленной Таблицы 7, препарат Мельдоний положительно влиял на РИ. В основной группе он увеличился на 0,08 Ом у пациентов с легкой степенью ХГП, на 0,05 - со средней степенью и на 0,04 ОМ с тяжелой степенью заболевания. В контрольной группе у пациентов с легкой степенью этот показатель увеличился на 0,93 Ом, средней - на 0,02, тяжелой — на 0,02 
Таблица 7. Динамика РИ (Ом) у больных ХГП, перенесших ИМ при лечении Мельдонием в зависимости от тяжести заболевания

\begin{tabular}{|l|l|l|l|l|}
\hline Степень тяжести ХГП & $\begin{array}{l}\text { Основная гр. } \\
\text { до лечения }(\mathbf{n = 1 4 0 )}\end{array}$ & $\begin{array}{l}\text { После лечения } \\
(\mathbf{n = 1 4 0 )}\end{array}$ & $\begin{array}{l}\text { Контрольная гр. } \\
\text { до лечения(n=90) }\end{array}$ & После лечения (n=90) \\
\hline ХГП легкой ст. & $0,08 \pm 0,01$ & $0,16 \pm 0,02^{*}$ & $0,08 \pm 0,01$ & $0,11 \pm 0,02^{*}$ \\
\hline ХГП средней ст. & $0,06 \pm 0,01$ & $0,11 \pm 0,02^{*}$ & $0,07 \pm 0,01$ & $0,09 \pm 0,01$ \\
\hline ХГП тяжелой ст. & $0,04 \pm 0,01$ & $0,08 \pm 0,01^{*}$ & $0,05 \pm 0,01$ & $0,07 \pm 0,01$ \\
\hline
\end{tabular}

$\mathrm{P}<0,05^{*} ; \mathrm{P}<0,01^{* *}$

Таблица 8. Динамика ПТС(\%) у больных ХГП, перенесших ИМ при лечении Мельдонием в зависимости от тяжести заболевания

\begin{tabular}{|l|l|l|l|l|}
\hline Степень тяжести ХГП & $\begin{array}{l}\text { Основная гр. } \\
\text { до лечения }(\mathbf{n = 1 4 0 )}\end{array}$ & $\begin{array}{l}\text { После лечения } \\
(\mathbf{n = 1 4 0 )}\end{array}$ & $\begin{array}{l}\text { Контрольная гр. } \\
\text { до лечения }(\mathbf{n = 9 0 )}\end{array}$ & $\begin{array}{l}\text { После лечения } \\
(\mathbf{n = 9 0})\end{array}$ \\
\hline ХГП легкой ст. & $18,8 \pm 0,9$ & $13,6 \pm 0,4^{*}$ & $18,4 \pm 0,8$ & $15,3 \pm 0,4$ \\
\hline ХГП средней ст. & $24,8 \pm 1,5$ & $18,5 \pm 0,8^{*}$ & $24,9 \pm 1,6$ & $20,1 \pm 0,9$ \\
\hline ХГП тяжелой ст. & $28,2 \pm 1,6$ & $23,2 \pm 1,4^{*}$ & $28,1 \pm 1,6$ & $25,2 \pm 1,4$ \\
\hline
\end{tabular}

Таблица 9. Динамика ИЭ(\%)у больных ХГП, перенесших ИМ при лечении Мельдонием в зависимости от тяжести ХГП

\begin{tabular}{|l|l|l|l|l|}
\hline Степень тяжести ХГП & $\begin{array}{l}\text { Основная гр. } \\
\text { до лечения }(\mathbf{n = 1 4 0 )}\end{array}$ & $\begin{array}{l}\text { После лечения } \\
(\mathbf{n = 1 4 0 )}\end{array}$ & $\begin{array}{l}\text { Контрольная гр. } \\
\text { до лечения(n=90) }\end{array}$ & После лечения (n=90) \\
\hline ХГП легкой ст. & $76,2 \pm 4,9$ & $85,4 \pm 5,2^{*}$ & $77,4 \pm 5,1$ & $81,5 \pm 5,2^{*}$ \\
\hline ХГП средней ст. & $71,2 \pm 5,1$ & $75,2 \pm 4,3^{*}$ & $71,5 \pm 4,6$ & $73,2 \pm 3,8$ \\
\hline ХГП тяжелой ст. & $67,6 \pm 4,2$ & $72,3 \pm 3,4^{*}$ & $68,1 \pm 3,6$ & $70,3 \pm 3,2$ \\
\hline
\end{tabular}

$\mathrm{P}<0,05^{*} ; \mathrm{P}<0,01^{* *}$

Ом. На фоне приема Мельдония значительно улучшился показатель ПТС (Таблица 8).

Как видно из представленной Таблицы 8, после курса терапии препаратом Мельдоний значительно улучшился ПТС, который достоверно снизился при всех степенях тяжести ХГП. В контрольной группе также наблюдалось снижение ПТС, однако изменения не имели степени достоверности. ИЭ, как известно отражает состояние тонуса сосудов. В Таблице 8 представлена динамика этого показателя под влиянием препарата Мельдоний.

Как видно из представленной Таблицы 9, показатели ИЭ имели положительную динамику и при легкой степени ХГП увеличились в основной группе на 9,2\%, средней - на 4,0, тяжелой - на 4,7\%. В контрольной группе динамика была менее выраженной и составила соответственно 4,1\%, 1,7 и 2,2\% соответственно.

В исследовании была проведена оценка влияния препарата Мельдоний на состояние пародонта у пациентов, страдающих ХГП и перенесших ИМ. Больным было проведено лечение препаратом Мельдоний в дозе 250 мг х 2 раза в день в течение 3-х месяцев. Исследование пародонтологического статуса проводилось до начала лечения и спустя 3 месяца после лечения. Больные основной и контрольной группы получали стандартное лечение ХГП и ИБС. Полученные результаты показали, что в основной группе на 11,4\% увеличилось число лиц с легкой степенью ХГП, в то время как в контрольной группе число этих больных увеличилось лишь на 2,1\%. В группе пациентов со средней степенью тяжести ХГП, принимавших Мельдоний, число пациентов уменьшилось на 8,6\%, в контрольной группе - на 4,4\%. Среди пациентов с тяжелой степенью ХГП принимавших Мельдоний, после курса лечения число больных уменьшилось на 2,8\%, в контрольной группе - на 2,2\%. Представленные результаты указывают на положительное действие Мельдония на процессы метаболизма пародонта, что способствует более быстрому устранению клинических проявлений ХГП. В ходе исследования был проведен анализ влияния препарата Мельдоний на показатель нуждаемости в лечении CPITN который показал инволюцию имевшихся симптомов. А именно - препарат Мель- 
доний уменьшил симптомы кровоточивости в группе со средней степенью заболевания улучшение этого показателя наблюдалось у 5,6\%, в контрольной - у 3,1\%. При тяжелой степени ХГП показатель кровоточивости десен в основной группе снизился на 5,4\%, в контрольной на $3,2 \%$.

В процессе лечения Мельдонием число пациентов с зубным камнем в основной группе уменьшилось у пациентов с легкой степенью ХГП на 15,6\%, при средней степени заболевания - на 12,1, при тяжелой - на 7,0\%. В контрольной группе динамика была менее выраженной и при ХГП легкой степени составила $10 \%$, средней степени - 7,8, тяжелой - 6,7\%. Прием препарата Мельдоний положительно влиял на процентное содержание пародонтальных карманов глубиной 4-5 мм. При ХГП легкой степени показатель уменьшился на 10,5\%, при средней степени - на 9,9, при тяжелой - на 8,4\%. В контрольной группе при ХГП легкой степени уменьшение произошло на 6,1\%, средней степени тяжести - на 5,9, тяжелой степени - на 4,4\%. При ХГП легкой степени, частота пародонтальных карманов глубиной 6 мм и более в основной группе уменьшились на 10,9\%, средней степени тяжести - на 6,6, тяжелой степени - на 3,6\%. Курсовое применение препарата Мельдоний оказало положительное влияние на показатели микроциркуляции в тканях пародонта, что выражалось в улучшении показателей реопародонтограммы. У больных ХГП легкой степени ИПС достоверно снижался в группе с легкой степенью заболевания на 13,3\%, средней степени - на 11,7, тяжелой степени - на 11,7\%. Препарат Мельдоний положительно влиял на РИ. В основной группе он увеличился на 0,08 Ом у пациентов с легкой степенью ХГП, на 0,05 со средней степенью и на 0,04 Ом с тяжелой степенью заболевания. На фоне приема Мельдония значительно улучшился показатель ПТС, который достоверно снизился при всех степенях тяжести ХГП. Показатели ИЭ также имели положительную динамику и при легкой степени ХГП увеличились в основной группе на 9,2\%, средней на 4,0, тяжелой - на 4,7\%.

\section{ЛИТЕРАТУРА}

1. Окуневич И.В., Рыженков В.Е. Антиатеросклеротическое действие Милдроната в эксперименте. Патологическая физиология и экспериментальная терапия 2002, № 2: 24-27.

2. Кузнецова А.В., Тепляков А.Т. Оценка влияния Кардионата на эффективность антиангинальной терапии и функциональное состояние миокарда у больных ИБС в сочетании с артериальной гипертензией, ассоциированной с сахарным диабетом 2 типа // РМЖ. 2009. № 4. С. $216-218$.

3. Напалков Д.А., Жиленко А.В. Цитопротекция в кардиологии: миф или реальность? // Фарматека. 2013. № 6. С. 111-115.

4. Третье универсальное определение инфаркта миокарда. Российский кардиологический журнал.2013;2(100). (Приложение 1),

5. Рекомендации по лечению артериальной гипертонии. ESH/ESC2013 С. 15-38.

6. Клинические рекомендации (протоколы лечения) при диагнозе пародонтит. Утверждены Решением Совета Ассоциации общественных объединений «Стоматологическая Ассоциация России» 23 апреля 2013 года с изменениями и дополнениями на основании Постановления № 18 Совета Ассоциации общественных объединений «Стоматологическая Ассоциация России» от 30 сентября 2014 года.

7. Рекомендации по лечению стабильной ишемической болезни сердца. Российский кардиологический журнал.№ 7(111)2014.

8. Oral infections as predictors of mortality / P. Hämäläinen, J.H. Meurman, M. Kauppinen, M. Keskinen // Gerodontology.— 2005.—Vol. 22, № 3.— P. 151-157.

9. XVI Пленум правления Всесоюзн. науч. общества стоматологов // Стоматология, № 4, 1984, — c. 4-5]. 